\title{
Nutrient Intakes from Food of Lactating Women Do Not Meet Many Dietary Recommendations Important for Infant Development and Maternal Health
}

\author{
Nathan S. Pratt1, Holiday A. Durham², Christina L. Sherry ${ }^{3 *}$ \\ ${ }^{1}$ University of Illinois Research Park, Abbott Nutrition, Champaign, USA \\ ${ }^{2}$ Department of Diabetes and Nutrition, Pennington Biomedical Research Center, Baton Rouge, USA \\ ${ }^{3}$ Department of Scientific and Medical Affairs, Abbott Nutrition, Columbus, USA \\ Email: christina.sherry@abbott.com
}

Received 9 July 2014; revised 12 August 2014; accepted 20 August 2014

Copyright (C) 2014 by authors and Scientific Research Publishing Inc.

This work is licensed under the Creative Commons Attribution International License (CC BY). http://creativecommons.org/licenses/by/4.0/

(c) () Open Access

\begin{abstract}
Literature describing dietary intakes of lactating mothers in the United States (US) is limited and none of the existing studies attempts to identify whether dietary shortcomings of lactating mothers are distinct from those of women of childbearing age in the US. The first objective of this observational study was to comprehensively analyze the dietary intakes of lactating mothers in the US to determine whether nutrient intakes from food were sufficient to meet recommendations. The second objective was to compare these intakes to those of women of childbearing age in the US. Weekly 3-day food records were collected from subjects for six weeks in 2012-2013. Subject mean daily intakes of food groups, macronutrients, vitamins, minerals, carotenoids, and specific fats including omega-3 and omega- 6 fatty acids were determined and compared to daily recommendations. Intakes were compared to US women using the 2009-2010 National Health and Nutrition Examination Survey. Fruit, vegetable, and dairy intakes of mothers were $\leq 50 \%$ of recommendations, resulting in 12 of 26 analyzed vitamins or minerals including potassium, iodine, chromium, choline, and vitamins $A, D$, and $E$ having mean daily intakes below the Estimated Average Requirement. Vitamin D intake of subjects was $18 \%$ lower than US women, while most other nutrients showed intakes within $10 \%$ of each other between populations. Lactating women are not meeting the increased dietary needs associated with breastfeeding, supporting education initiatives and interventions specifically tailored to breastfeeding populations to increase intakes of vitamin D, vitamin E, iodine, biotin, carotenoids, and polyunsaturated fatty acids from food.
\end{abstract}

\footnotetext{
*Corresponding author.
}

How to cite this paper: Pratt, N.S., Durham, H.A. and Sherry, C.L. (2014) Nutrient Intakes from Food of Lactating Women Do Not Meet Many Dietary Recommendations Important for Infant Development and Maternal Health. Food and Nutrition Sciences, 5, 1644-1651. http://dx.doi.org/10.4236/fns.2014.517177 


\section{Keywords}

\section{Breastfeeding, Dietary Intake, Nutrition, Lactating}

\section{Introduction}

The nutritional needs of breastfeeding women are greater than any other time in her reproductive lifecycle, including pregnancy [1]. The benefits of breastfeeding on both maternal and infant health are well supported and $75 \%$ of mothers in the United States (US) initiate breastfeeding after delivery, contributing to reduced incidence of infant hospitalization as well as decreasing infant's risk for the development of long-term health outcomes such as diabetes and obesity [2]. Breastfeeding can significantly impact a woman's nutrition status and for many nutrients, including most minerals and folate, lactating women are at risk of depleting their nutrient stores if intake is inadequate [1]. For other nutrients, including vitamin A, many water soluble vitamins and polyunsaturated fatty acids (PUFAs), breast milk concentrations are responsive to maternal intake, allowing maternal diet to greatly influence breast milk composition and infant nutrition.

For the past 25 years, there has been a call for more data on the nutrient intakes of lactating women given their unique dietary needs and that many women of childbearing age in the US may already be at risk of insufficient intakes of nutrients critical for pregnancy and lactation [3] [4]. However, very little research exists that analyzes the dietary intakes of lactating women; most studies are designed to understand specific nutrients rather than comprehensively analyze the diet and risk for inadequacy [5]-[7]. A few studies focus on subpopulations of lactating women, including those who are dieting [8], overweight/obese [9], or highly educated [10]. While these studies show that many lactating women consume diets insufficient in nutrients critical for maternal and infant health, the varied study designs make it difficult to draw conclusions about general dietary patterns.

Furthermore, many educational initiatives aimed at improving dietary intakes of lactating women are based on dietary patterns of women from the National Health and Nutrition Examination Survey (NHANES). However, NHANES does not describe dietary intakes of lactating women separately from women of childbearing age despite the differing nutrient requirements between these populations [4], and none of the previous studies attempt to identify if dietary shortcomings of lactating women are unique from those of women of childbearing age.

The goal of this study was to help establish a baseline understanding of the diet of lactating women to determine the areas of improvement by 1) comprehensively analyzing nutrient intakes from food as well as 2) comparing these intakes to those of women of childbearing age in the US to identify dietary shortcomings unique to lactating women. Taken together, these results can be used to develop targeted interventions and education initiatives to improve dietary behaviors of lactating women based on their unique dietary patterns and needs. By providing a baseline nutrient intake from food alone, these results can also serve to inform healthcare professionals if specific supplementation should be recommended for this population.

\section{Subjects \& Methods}

\subsection{Subjects and Study Design}

All subjects in the study were 4 - 6 weeks post-partum at enrollment and were part of a six-week prospective, randomized, placebo-controlled dose response study to examine the impact of lutein, docosohexaenoic acid (DHA) and vitamin E supplementation in lactating women and their infants; all subject characteristics and demographics are previously described [11]. Briefly, all data was collected between fall of 2012 and spring of 2013 from a cohort of lactating women in the midwestern United States. Participants were $\geq 18$ years of age, had a full-term singleton delivery, had been continuously, successfully lactating and planned to continue for at least six weeks. Mothers with a BMI $\geq 30 \mathrm{~kg} / \mathrm{m}^{2}$ or taking cholesterol medication and/or other medications affecting lipid absorption and/or transport were excluded from the study. All subjects were pooled for the dietary analysis, as the intervention of the primary study did not include dietary counseling. Only subject characteristics and measures of dietary intake from food are currently presented. Nutrient intake from supplements is not included as this information was not collected in the primary study. Mothers were primarily breastfeeding, providing an average of 7.4 breast milk feedings/day and 0.6 formula feedings/day. Height and weight of subjects were col- 
lected via medical records. This study was conducted in accordance with Good Clinical Practice and International Conference of Harmonization and was approved by the Copernicus Group Institutional Review Board. Written, informed consent was obtained from all subjects before enrollment.

\subsection{Dietary Assessment and Analysis}

Dietary intake of subjects was measured using weekly 3-day food records throughout the six-week primary study. During the baseline visit, subjects met with the study nurse at their respective site to be trained with materials describing how to properly record food intakes and estimate serving sizes and then asked to record all foods and beverages consumed for three days of their choosing weekly for six weeks. At each subsequent visit, the previous week's diet record was reviewed with the study nurse for accuracy before submission to a trained nutrition technician for entry into the analysis software. Subjects continued their normal diet for the duration of the study; aside from consumption of the DHA/lutein/vitamin E supplement or placebo for the primary study, no specific dietary instruction was provided.

Food records were screened by the researchers to clarify any missing data or questions and then entered into The Food Processor ${ }^{\circledR}$ dietary analysis software (version 10.12.0, 2012, ESHA Research); foods available in the database can be found at http://download.esha.com/fandc/sqlfc.pdf. USDA-sourced data were used when selecting foods from the database to minimize missing nutrient information. Age, height, weight and physical activity (PA) level for each individual were used to allow personalized food group and nutrient recommendations to be generated for each subject. Food group recommendations were based on My Plate (http://choosemyplate.gov), the standard nutrition guidance tool used in the US published by the US Department of Agriculture (USDA), which provides recommendations for fruit, vegetable, protein, grain, and dairy intakes per day for specific populations including breastfeeding women. Since PA of subjects was not a recorded measure in the primary study, all subjects were given a "lightly active" PA level for this analysis, which is defined as 1 - 1.5 hours of total PA per day (light-moderate \& walking) and consistent with total activity levels of eight hours per week of early postpartum women [12].

Summaries of each subject's mean daily nutrient intakes from food and mean daily intake of MyPlate food group servings over the six-week study were generated. Food group intake as a percentage of MyPlate recommendations and total number of subjects meeting these recommendations was determined for all food groups. Mean daily nutrient intakes from food were compared to the Estimated Average Requirements (EAR) and/or Recommended Daily Allowances (RDA) as a percentage of these recommendations. Adequate Intake values (AI) were used for nutrients without EARs.

Mean daily nutrient intakes were compared to nutrient intakes from food of women of childbearing age using data from the NHANES 2009-2010 [4]. Since there is no data specifically for lactating women in the NHANES report, mean intake from food for women of childbearing age was calculated as a weighted average based on the sample size for 20 - 29, 30 - 39, and 40 - 49 age categories for women from the NHANES report. Mean daily intakes were then calculated as a percentage of mean intakes of women of childbearing age.

\section{Results and Discussion}

A total of 83 subjects (94.3\%) completed at least five of the six weekly 3-day food records. The remaining five subjects completed at least one 3-day food record, as they exited the primary study early [11], and were included in this analysis because their dietary patterns were similar to those of subjects that completed the study. A total of 1518 food records were collected and analyzed, 360 (23.7\%) of which were from weekend days. Most subjects were White $(n=78)$, while eight and two declared their race as Black or Other, respectively. The mean age was 28.9 years and 11 participants were greater than 35 years of age. The average BMI was $24.0 \mathrm{~kg} / \mathrm{m}^{2}$, although 39 of the 88 participants were overweight.

\subsection{MyPlate and NHANES}

Mean daily intakes of MyPlate food groups are presented in Table 1 and compared to individualized MyPlate recommendations. Mean intakes of fruits, vegetables, and dairy were $\leq 50 \%$ of recommended daily servings. Despite protein and grain intakes being closer to recommendations, only a minority of subjects met their recommended daily ounce equivalents for these food groups. The consumption trends of the current cohort may be 
Table 1. Mean daily food group intake of a cohort of lactating women compared to USDA recommendations from MyPlate ${ }^{\mathrm{a}}$.

\begin{tabular}{cccc}
\hline Food Group & $\begin{array}{c}\text { Average } \\
\text { Recommendation }\end{array}$ & $\begin{array}{c}\text { Daily Intake } \\
\text { (\% Recommendation) }\end{array}$ & $\begin{array}{c}\text { Subjects Meeting Recommendations } \\
\text { (\% of Population) }\end{array}$ \\
Fruit & 2 cups & $1.0(50.2)$ & $11(12.5)$ \\
Vegetable & 3.1 cups & $1.4(44.4)$ & $1(1.1)$ \\
Protein & 6.5 ounces & $5.9(90.1)$ & $30(34.1)$ \\
Grain & 8.2 ounces & $6.4(77.7)$ & $12(13.6)$ \\
Dairy & 3 cups & $1.5(50.9)$ & $5(5.7)$
\end{tabular}

${ }^{\mathrm{a}}$ All data is daily average of all subjects over 6 weeks $(\mathrm{n}=88)$; ${ }^{\mathrm{b}}$ Food group recommendations (cup- or ounce-equivalents) were calculated for each subject based on individual height, weight, light activity level and life-category (lactating) using USDA guidelines (http://www.myplate.gov).

mirroring eating patterns of US women, who showed mean consumptions of 1.0 cup of fruit, 1.5 cups of vegetables, 1.3 cups of dairy, 5.6 ounces (oz) of grains and 4.9 oz of protein in 2007-2008 [13]. While fruit, vegetable, and dairy intakes are similar between these two populations, protein and grain intakes of lactating women in this study are $20 \%$ and $14 \%$ higher, respectively, than those shown for US women, suggesting that lactating women may compensate for their increased nutrition demands by increasing intake of foods from the protein and grain food groups without a corresponding increase in fruit, vegetable, and dairy foods. This finding is in agreement with results from a study in overweight lactating women that found protein and grain intakes to be much closer to recommendations than fruit, vegetable, and dairy intakes [9], the latter of which are food groups containing many vitamins and minerals whose needs increase during lactation.

\subsection{Intakes of Individual Nutrients}

The mean daily intakes from food of macronutrients, selected PUFAs, carotenoids, water, and caffeine are shown in Table 2 alongside the mean intakes of US women aged 20 - 49 years old for these nutrients [4]. Carbohydrate, fat and protein intakes all fell within their respective Acceptable Macronutrient Distribution Ranges (AMDR) [14], although fat intake was near the upper limit of the AMDR. Conversely, carbohydrate intake was near the lower end of the AMDR; paired with the low fruit and vegetable intakes described above, this may have contributed to the mean daily fiber intake of $<60 \%$ of the AI for fiber [14].

The various intakes of PUFAs from foods are shown in Table 2. The intake of omega-3 (n3) and omega-6 (n6) fatty acids were close to the AI for these nutrients but near the lower end of their AMDR [14]. Intakes of the highly unsaturated fatty acids (HUFA) arachidonic acid (AA), docosahexaenoic acid (DHA) and eicosapentaenoic acid (EPA) were close to the national average intakes of women of childbearing age [4]. Although there is no specific Dietary Reference Intake (DRI) for DHA, EPA, or AA, numerous recommendations exist for the intake of these HUFAs [15], including recommendations for lactating women to consume of $200 \mathrm{mg}$ [16] to 300 mg [17] of DHA daily. The mean intake was 31.2\% of the $200 \mathrm{mg} /$ day recommendation, with only 3 subjects (3\%) meeting this recommendation on average. Since DHA has been shown to be important for neural development in infancy [18], low dietary intakes of DHA among lactating women could present a concern for neural development of breastfed infants.

Mean intakes of the carotenoids lycopene and lutein + zeaxanthin from food are shown in Table 2. While specific recommendations do not exist for these carotenoids, one can estimate prudent intakes based on carotenoid consumption of individuals meeting fruit and vegetable recommendations, the primary dietary source of carotenoids [19]. Prudent intakes range from 8 - $9 \mathrm{mg} / \mathrm{d}$ [20] for lycopene and $4-7 \mathrm{mg} / \mathrm{d}$ of lutein + zeaxanthin [21] and are more than double the intakes in the current cohort; only 5 and 6 subjects $(<7 \%)$, respectively, achieved mean daily intakes from food within these ranges. These findings support the promotion of carotenoid-rich fruit and vegetable intake for lactating women, as lycopene has been shown to be an important antioxidant in both mother and infant health [22] while lutein has a critical role in development of the fovea in the first four months of life [23] and concentrations of lutein in breast milk are highly correlated with maternal intake [11].

\subsection{Vitamin and Mineral Intake Compared to Recommendations and NHANES Intakes}

The mean vitamin and mineral intakes from food are shown in Table 3 and compared to the respective EARs 
Table 2. Mean daily nutrient intakes from food for calories, selected fatty acids and carotenoids, water, and caffeine compared to daily recommendations for lactating women and intakes of women of childbearing age in the United States.

\begin{tabular}{|c|c|c|c|}
\hline Nutrient & $\begin{array}{c}\text { Daily Intake } \\
\text { (mean \% contribution to total calories) }^{\mathrm{a}}\end{array}$ & DRI Recommendation ${ }^{\mathrm{b}}$ & $\begin{array}{c}\text { NHANES Intake } \\
\text { (mean \% contribution to total calories) }\end{array}$ \\
\hline Calories & 1934 & & 1857 \\
\hline Carbohydrate (g) & $240.7(49.0)$ & $45 \%-65 \%$ of calories ${ }^{c}$ & $236.6(51.3)$ \\
\hline Fiber (g) & 17.3 & $29^{d}$ & 15.1 \\
\hline Sugar (g) & 97.4 & $*$ & 109.7 \\
\hline Protein (g) & $79.7(16.4)$ & $10 \%-35 \%$ of calories ${ }^{c}$ & $69.6(15.7)$ \\
\hline Fat (g) & $75.1(34.4)$ & $20 \%-35 \%$ of calories ${ }^{c}$ & $67.9(32.3)$ \\
\hline Saturated (g) & $26.2(11.9)$ & As low as possible & $22.3(10.6)$ \\
\hline Monounsaturated (g) & $24.8(11.4)$ & $*$ & $24.0(11.3)$ \\
\hline Polyunsaturated (g) & $14.1(6.5)$ & * & $15.4(7.4)$ \\
\hline n-6 fatty acids (g) & $12.1(5.9)$ & $13 \mathrm{~g}(5 \%-10 \% \text { of calories })^{d}$ & $\mathrm{n} / \mathrm{a}$ \\
\hline $\begin{array}{l}\text { Linoleic acid } \\
(18: 2 n-6)(g)\end{array}$ & 11.94 & * & 13.6 \\
\hline $\begin{array}{l}\text { Arachidonic acid } \\
(20: 4 n-6)(g)\end{array}$ & 0.13 & * & 0.12 \\
\hline $\mathrm{n}-3$ fatty acids (g) & $1.33(0.6)$ & $1.3 \mathrm{~g}(0.6 \%-1.2 \% \text { of calories })^{\mathrm{d}}$ & $\mathrm{n} / \mathrm{a}$ \\
\hline $\begin{array}{c}\alpha \text {-Linolenic acid } \\
(18: 3 \mathrm{n}-3)(\mathrm{g})\end{array}$ & 1.21 & $*$ & 1.36 \\
\hline $\begin{array}{l}\text { Docosahexaenoic acid } \\
(22: 6 \mathrm{n}-3)(\mathrm{g})\end{array}$ & 0.06 & $*$ & 0.06 \\
\hline $\begin{array}{l}\text { Eicosapentaenoic acid } \\
(20: 5 n-3)(g)\end{array}$ & 0.03 & * & 0.03 \\
\hline Trans-fatty acids (g) & $1.1(0.5)$ & As low as possible & $\mathrm{n} / \mathrm{a}$ \\
\hline Other $^{e}$ & $8.9(4.1)$ & $*$ & $\mathrm{n} / \mathrm{a}$ \\
\hline Lycopene (mg) & 4.1 & $*$ & 4.8 \\
\hline Lutein + zeaxanthin (mg) & 1.7 & * & 1.4 \\
\hline Water (g) & 2248 & 3800 & $\mathrm{n} / \mathrm{a}$ \\
\hline Caffeine (mg) & 76.9 & * & 144 \\
\hline
\end{tabular}

${ }^{a}$ All data is daily average of all subjects over 6 weeks $(n=88)$; ${ }^{b}$ Recommendations refer to Dietary Reference Intakes (DRI) specific to lactating women 19 - 50 y; ${ }^{\mathrm{c}}$ Acceptable Macronutrient Distribution Range (AMDR); ${ }^{\mathrm{d}}$ Adequate Intake (AI); ${ }^{\mathrm{e}} \mathrm{Fat}$ type not further specified in database. ${ }^{*}$ Nutrient does not have an established DRI. n/a: data not available.

and RDAs. Twelve of the 26 nutrients had mean intakes below the EAR or AI. Very few subjects met daily recommendations for vitamin $D(n=2)$, vitamin $E(n=1)$, potassium $(n=0)$, iodine $(n=1)$, chromium $(n=1)$ and choline $(n=0)$ on average, leading to mean daily intakes of these nutrients from food averaging $<50 \%$ of recommendations. The intakes of 20 - 49-year-old women from the 2009-2010 NHANES for most nutrients including vitamin E, potassium, and choline are within $10 \%$ of the intake of the current cohort. Since requirements for many of these nutrients increase during lactation, these results suggest that lactating women are not appropriately increasing their fruit, vegetable, and dairy intake relative to their pre-breastfeeding dietary behavior to compensate for these increased nutrient needs. Vitamin D intake was $18.2 \%$ lower than US women, and much lower than the 5 - 6 mcg/d previously shown for mixed- or fully-breastfeeding women [9], supporting the inclusion of this nutrient on the "nutrients to increase" list in the Dietary Guidelines for Americans 2010 [24]. It is likely that the low dietary intake of iodine can be partially attributed to the low dairy intake, as dairy is the largest contributor of iodine in the US diet, while iodized salt typically accounts for a small amount of dietary iodine [25]. Based on these results, placing special emphasis on consumption of milk and dairy products to lactating women could be a plausible public health message to help in alleviating problems in maternal and infant health associated with low iodine and vitamin D intakes such as decreased mental development in the infant [26] 
Table 3. Vitamin/mineral intake from food as compared to recommendations for lactating women and intakes of women of childbearing age in the United States ${ }^{\mathrm{a}}$.

\begin{tabular}{|c|c|c|c|c|}
\hline Nutrient & Daily Intake ${ }^{\mathrm{b}}$ & $\operatorname{EAR}\left(\%{ }^{* *}\right)^{c}$ & $\operatorname{RDA}\left(\%{ }^{* *}\right)$ & $\begin{array}{c}\text { Mean intake of US } \\
\text { women, } 20-49 \mathrm{y}^{\mathrm{d}}\left(\%^{* * *}\right)\end{array}$ \\
\hline Vitamin A (mcg RAE) & 646.1 & $900(71.8)$ & $1,300(49.7)$ & $564.0(114.6)$ \\
\hline Vitamin C (mg) & 80.2 & $100(80.2)$ & $120(66.8)$ & $78.8(101.8)$ \\
\hline Calcium (mg) & 888.0 & $800(111.0)$ & $1000(88.8)$ & $922.0(96.3)$ \\
\hline Iron (mg) & 14.7 & $6.5(226.2)$ & $9(165.3)$ & $13.5(108.9)$ \\
\hline Vitamin D (mcg) & 3.6 & $10(36.0)$ & $15(24.0)$ & $4.4(81.8)$ \\
\hline Vitamin E ( $\alpha$-tocopherol) (mg) & 6.3 & $16(39.4)$ & $19(33.2)$ & $6.9(91.3)$ \\
\hline Vitamin K (mcg) & 102.4 & $90(113.8)$ & * & $93.2(109.9)$ \\
\hline Thiamin (mg) & 1.5 & $1.2(125.0)$ & $1.4(107.1)$ & $1.4(107.1)$ \\
\hline Riboflavin (mg) & 1.8 & $1.3(138.5)$ & $1.4(128.6)$ & $1.8(100)$ \\
\hline Niacin (mg NE) & 35.0 & $13(269.2)$ & $18(194.4)$ & $21.4(163.6)$ \\
\hline Pantothenic Acid (mg) & 4.7 & $7(67.1)$ & $*$ & $\mathrm{n} / \mathrm{a}$ \\
\hline Vitamin B6 (mg) & 1.8 & $1.7(105.9)$ & $2(90)$ & $1.7(105.9)$ \\
\hline Folate (mcg DFE) & 492.2 & $450(109.3)$ & $500(98.4)$ & $462.0(106.5)$ \\
\hline Vitamin B12 (mcg) & 4.2 & $2.4(175.0)$ & $2.8(150.0)$ & 4.7 (89.4) \\
\hline Biotin (mcg) & 18.4 & 35 (52.6) & $*$ & $\mathrm{n} / \mathrm{a}$ \\
\hline Sodium (mg) & 3045.0 & $1500(203.0)$ & * & 3092 (98.5) \\
\hline Potassium (mg) & 2345.5 & $5100(46.0)$ & * & $2346(100)$ \\
\hline Phosphorous (mg) & 1234.3 & $580(212.8)$ & $700(176.3)$ & $1220(101.2)$ \\
\hline Iodine (mcg) & 62.0 & 209 (29.7) & $290(21.4)$ & $\mathrm{n} / \mathrm{a}$ \\
\hline Magnesium (mg) & 253.7 & 255 (99.5) & 310 - 320 (81.8) & $268.0(94.7)$ \\
\hline Zinc (mg) & 10.2 & $10.4(98.1)$ & $12(85.0)$ & $10.0(102.0)$ \\
\hline Selenium (mcg) & 97.5 & 59 (165.3) & 70 (139.3) & 95.8 (101.8) \\
\hline Copper (mg) & 1.1 & $1(110.0)$ & $1.3(84.6)$ & $1.1(100)$ \\
\hline Manganese (mg) & 2.8 & $2.6(107.7)$ & * & $\mathrm{n} / \mathrm{a}$ \\
\hline Chromium (mcg) & 7.4 & $45.0(16.4)$ & * & $\mathrm{n} / \mathrm{a}$ \\
\hline Choline (mg) & 252.8 & $550(46.0)$ & * & $274.0(92.3)$ \\
\hline
\end{tabular}

${ }^{\mathrm{a}}$ Recommendations are Recommended Dietary Allowance (RDA) and Estimated Average Requirments (EAR) for lactating women 19 - 50 y; ${ }^{\mathrm{b}}$ All data is daily average of all subjects over 6 weeks $(n=88) ;{ }^{c}$ Adequate Intake (AI) used for nutrients that do not have an EAR; ${ }^{\mathrm{d}}$ Mean intake calculated as a weighted average based on the sample size for 20 - 29, 30 - 39, and 40 - 49 age categories for women from National Health and Nutrition Examination Survey (NHANES) 2009-2010 [4]. " Nutrients do not have an EAR; no RDA established; ${ }^{* *}$ Mean daily intake of the cohort was calculated as a percentage of the EAR and RDA for lactating women; ${ }^{* * *}$ Mean daily intake of the cohort was calculated as a percentage of the intakes of women of childbearing age in the US as defined by NHANES; n/a: data not available.

and decline in numerous health categories including bone health [27], respectively. Observed vitamin A, iron, and folate intakes were $6.5 \%$ - 14.6\% above those of US women, with iron and folate well above the EARs for lactating women. Similarly high intakes relative to US women were previously shown in lactating women for iron and folate [9], suggesting that food fortification and education to pregnant women emphasizing the importance of these nutrients are successful in leading to dietary change and may have lingering effects postpartum. 


\section{Conclusions}

This study helps establish a fundamental understanding of the baseline nutrient intake from food in lactating women and reveals how these patterns differ from women of childbearing age to inform education and intervention specific to this population. The results of this study are mostly in agreement with previous studies done in lactating women, which identify vitamins A, C, D, and E as nutrients of concern [9] [10], while also presenting new findings providing concern for dietary intakes of iodine, biotin, and carotenoids. In fact, intakes for most nutrients in this study are actually lower than the aforementioned studies, although it is difficult to compare as the other study populations were limited to a university setting [9] or overweight women [10].

The Institute of Medicine encourages lactating women to rely on food rather than supplements to meet dietary recommendations for nutrients [1]; however, as currently demonstrated, food alone does not seem to meet the nutrient needs for this breastfeeding population. Supplementation may be one way to help overcome inadequate nutrient intakes from food alone, as it was seen that subjects in the primary study receiving the intervention supplement were only able to meet the ideal intake of DHA, lutein and vitamin due to their use of the intervention supplement (data not shown). The small body of research that exists about micronutrient supplementation during breastfeeding suggests that most lactating women consume a multivitamin/mineral supplement, but there are no consensus recommendations regarding supplementation during breastfeeding despite the fact that most nutrient needs during lactation are higher than those of pregnancy [28].

Our results suggest that the low intakes of many nutrients critical during lactation can largely be attributed to inadequate intakes of fruit, vegetable, dairy, and oily fish. Furthermore, differences in dietary intakes of many food groups and nutrients between the current cohort and women of childbearing age emphasize the importance of separately considering the two populations when discussing dietary interventions and education. Thus, the results of this study provide compelling support for dietary education to lactating women that specifically emphasizes increasing intake of nutrients such as vitamin D, vitamin E, vitamin A, iodine, and biotin as well as carotenoids and PUFAs. This may be accomplished through further education to lactating women on the importance of increasing their consumption of fruits, vegetables, dairy, and oily fish.

\section{Acknowledgements}

The authors would like to thank the study team members and participants. The study was supported by Abbott Nutrition. HAD supported in part by 1 U54 GM104940 from the National Institute of General Medical Sciences of the National Institutes of Health which funds the Louisiana Clinical and Translational Science Center.

\section{References}

[1] National Research Council (1991) Nutrition during Lactation. The National Academies Press, Washington DC.

[2] Johnston, M.L.S., Noble, L., Szucs, K. and Viehmann, L. (2012) Breastfeeding and the Use of Human Milk. Pediatrics, 129, e827-e841. http://dx.doi.org/10.1542/peds.2011-3552

[3] US Congress (1990) National Nutrition Monitoring and Related Research Act of 1990. US G.P.O., Washington DC.

[4] US Department of Agriculture ARS (2012) Total Nutrient Intakes: Percent Reporting and Mean Amounts of Selected Vitamins and Minerals from Food, by Family Income (as \% of Federal Poverty Threshold) and Age. US Department of Agriculture ARS, Beltsville.

[5] Bougma, K., Aboud, F.E., Harding, K.B. and Marquis, G.S. (2013) Iodine and Mental Development of Children 5 Years Old and Under: A Systematic Review and Meta-Analysis. Nutrients, 5, 1384-1416. http://dx.doi.org/10.3390/nu5041384

[6] Antonakou, A., Chiou, A., Andrikopoulos, N.K., Bakoula, C. and Matalas, A.L. (2011) Breast Milk Tocopherol Content during the First Six Months in Exclusively Breastfeeding Greek Women. European Journal of Nutrition, 50, 195-202. http://dx.doi.org/10.1007/s00394-010-0129-4

[7] Sherwood, K.L., Houghton, L.A., Tarasuk, V. and O’Connor, D.L. (2006) One-Third of Pregnant and Lactating Women May Not Be Meeting Their Folate Requirements from Diet Alone Based on Mandated Levels of Folic Acid Fortification. Journal of Nutrition, 136, 2820-2826.

[8] Lovelady, C.A., Stephenson, K.G., Kuppler, K.M. and Williams, J.P. (2006) The Effects of Dieting on Food and Nutrient Intake of Lactating Women. Journal of the American Dietetic Association, 106, 908-912. http://dx.doi.org/10.1016/j.jada.2006.03.007

[9] Durham, H.A., Lovelady, C.A., Brouwer, R.J., Krause, K.M. and Ostbye, T. (2011) Comparison of Dietary Intake of 
Overweight Postpartum Mothers Practicing Breastfeeding or Formula Feeding. Journal of the American Dietetic Association, 111, 67-74. http://dx.doi.org/10.1016/j.jada.2010.10.001

[10] Mackey, A.D., Picciano, M.F., Mitchell, D.C. and Smiciklas-Wright, H. (1998) Self-Selected Diets of Lactating Women Often Fail to Meet Dietary Recommendations. Journal of the American Dietetic Association, 98, $297-302$. http://dx.doi.org/10.1016/S0002-8223(98)00070-4

[11] Sherry, C.L., Oliver, J.S., Renzi, L.M. and Marriage, B.J. (2014) Lutein Supplementation Increases Breast Milk and Plasma Lutein Concentrations in Lactating Women and Infant Plasma Concentrations but Does Not Impact Other Carotenoids. Journal of Nutrition, 144, 1256-1263. http://dx.doi.org/10.3945/jn.114.192914

[12] Pereira, M.A., Rifas-Shiman, S.L., Kleinman, K.P., Rich-Edwards, J.W., Peterson, K.E. and Gillman, M.W. (2007) Predictors of Change in Physical Activity during and after Pregnancy: Project Viva. American Journal of Preventive Medicine, 32, 312-319. http://dx.doi.org/10.1016/j.amepre.2006.12.017

[13] Sebastian, R.S., Enns, C.W. and Goldman, J.D. (2011) MyPyramid Intakes and Snacking Patterns of US Adults: What We Eat in America, NHANES 2007-2008. Food Surveys Research Group, Agriculture USDo.

[14] National Research Council (2005) Dietary Reference Intakes for Energy, Carbohydrate, Fiber, Fat, Fatty Acids, Cholesterol, Protein and Amino Acids (Macronutrients). The National Academies Press, Washington DC.

[15] Kris-Etherton, P.M., Grieger, J.A. and Etherton, T.D. (2009) Dietary Reference Intakes for DHA and EPA. Prostaglandins, Leukotrienes and Essential Fatty Acids, 81, 99-104. http://dx.doi.org/10.1016/j.plefa.2009.05.011

[16] Koletzko, B., Lien, E., Agostoni, C., Bohles, H., Campoy, C., Cetin, I., et al. (2008) The Roles of Long-Chain Polyunsaturated Fatty Acids in Pregnancy, Lactation and Infancy: Review of Current Knowledge and Consensus Recommendations. Journal of Perinatal Medicine, 36, 5-14. http://dx.doi.org/10.1515/JPM.2008.001

[17] Simopoulos, A.P., Leaf, A. and Salem Jr., N. (1999) Workshop on the Essentiality of and Recommended Dietary Intakes for Omega-6 and Omega-3 FATTY Acids. Asia Pacific Journal of Clinical Nutrition, 8, 300-301. http://dx.doi.org/10.1046/j.1440-6047.1999.00123.x

[18] Carlson, S.J., Fallon, E.M., Kalish, B.T., Gura, K.M. and Puder, M. (2013) The Role of the Omega-3 Fatty Acid DHA in the Human Life Cycle. Journal of Parenteral and Enteral Nutrition, 37, 15-22. http://dx.doi.org/10.1177/0148607112467821

[19] National Research Council (2000) Dietary Reference Intakes for Vitamin C, Vitamin E, Selenium, and Carotenoids. The National Academies Press, Washington DC.

[20] Murphy, M.M., Barraj, L.M., Herman, D., Bi, X., Cheatham, R. and Randolph, R.K. (2012) Phytonutrient Intake by Adults in the United States in Relation to Fruit and Vegetable Consumption. Journal of the Academy of Nutrition and Dietetics, 112, 222-229. http://dx.doi.org/10.1016/j.jada.2011.08.044

[21] Kruger, C.L., Murphy, M., DeFreitas, Z., Pfannkuch, F. and Heimbach, J. (2002) An Innovative Approach to the Determination of Safety for a Dietary Ingredient Derived from a New Source: Case Study Using a Crystalline Lutein Product. Food and Chemical Toxicology, 40, 1535-1549. http://dx.doi.org/10.1016/S0278-6915(02)00131-X

[22] Clinton, S.K. (1998) Lycopene: Chemistry, Biology, and Implications for Human Health and Disease. Nutrition Reviews, 56, 35-51.

[23] Zimmer, J.P. and Hammond Jr., B.R. (2007) Possible Influences of Lutein and Zeaxanthin on the Developing Retina. Clinical Ophthalmology, 1, 25-35.

[24] McGuire, S., US Department of Agriculture and US Department of Health and Human Services (2011) Dietary Guidelines for Americans, 2010. Advances in Nutrition, 2, 293-294.

[25] Caldwell, K.L., Pan, Y., Mortensen, M.E., Makhmudov, A., Merrill, L. and Moye, J. (2013) Iodine Status in Pregnant Women in the National Children's Study and in US Women (15 - 44 Years), National Health and Nutrition Examination Survey 2005-2010. Thyroid, 23, 927-937. http://dx.doi.org/10.1089/thy.2013.0012

[26] Zimmermann, M.B. (2007) The Adverse Effects of Mild-to-Moderate Iodine Deficiency during Pregnancy and Childhood: A Review. Thyroid, 17, 829-835. http://dx.doi.org/10.1089/thy.2007.0108

[27] Vieth, R., Bischoff-Ferrari, H., Boucher, B.J., Dawson-Hughes, B., Garland, C.F., Heaney, R.P., et al. (2007) The Urgent Need to Recommend an Intake of Vitamin D That Is Effective. American Journal of Clinical Nutrition, 85, 649650.

[28] Picciano, M.F. and McGuire, M.K. (2009) Use of Dietary Supplements by Pregnant and Lactating Women in North America. American Journal of Clinical Nutrition, 89, 663S-667S. http://dx.doi.org/10.3945\%2Fajcn.2008.26811B 
Scientific Research Publishing (SCIRP) is one of the largest Open Access journal publishers. It is currently publishing more than 200 open access, online, peer-reviewed journals covering a wide range of academic disciplines. SCIRP serves the worldwide academic communities and contributes to the progress and application of science with its publication.

Other selected journals from SCIRP are listed as below. Submit your manuscript to us via either submit@scirp.org or Online Submission Portal.
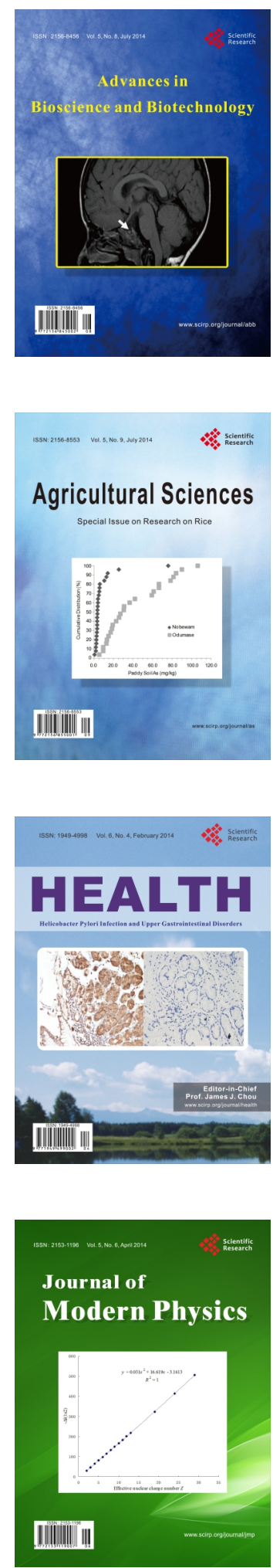
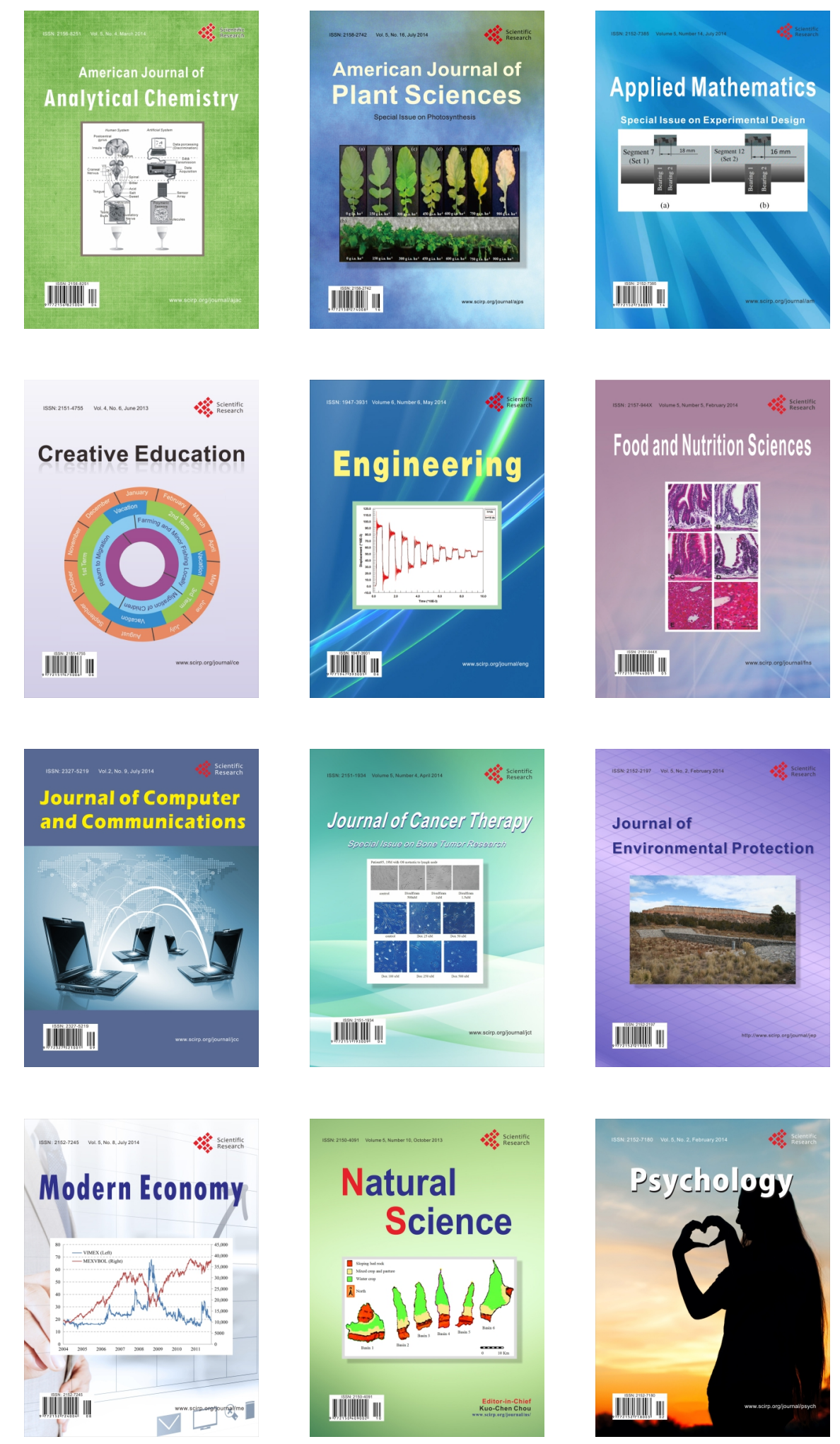